\title{
ANALYSIS OF DAMPING CHARACTERISTICS OF A CABLE STAYED BRIDGE BASED ON STRONG MOTION RECORDS
}

\author{
By Kazuhiko KAWASHIMA*, Shigeki UNJOH** and Youichi AZUTA***
}

\begin{abstract}
Damping characteristics are significant factors for seismic design of a cable stayed bridge. It is general in seismic design to assume a damping ratio of approximately $2-5 \%$ of critical for superstructure. However, damping ratio which has so far been estimated from field observation such as forced vibration test is generally much smaller than those values. This study presents an analysis on the damping characteristics of a cable stayed bridge where strong motion records have been accumulated. Damping characteristics are analyzed through analytical simulation for the measured response by varying the damping ratio assumed in the analysis. It is concluded from the analysis that the damping ratio which gives the best correlation in response analysis simulation is $2 \%$ and $0-1 \%$ of critical in longitudinal and transverse direction, respectively, for the tower, and $5 \%$ in both directions for the deck.

Keywords: cable stayed bridge, damping characteristics, strong motion records, seismic design
\end{abstract}

\section{INTRODUCTION}

Although cable stayed bridges have been constructed at various countries, little is known about the seismic behavior subjected to a significant earthquake. Special interests are extended to damping characteristics of cable stayed bridges. It is often claimed that the damping ratio assumed in seismic design is much larger than that assumed in wind resistant design. It is general in seismic design to assume a damping ratio of approximately $2-5 \%$ of critical for superstructure. However, damping ratio which has so far been estimated from field observation such as forced vibration test is generally much smaller than those values. Damping ratio of superstructure in vertical direction often takes a value far less than $1 \%$ of critical $^{1 \text { ). } 2)}$. Reflecting those evidences, the damping ratio assumed in wind resistant design is considerably smaller than the value assumed in seismic design. Because the structural response of a cable stayed bridge significantly depends on the damping ratio, correct estimation of the damping ratio is of critical importance in seismic design of a cable stayed bridge.

Because evaluation of the damping characteristics of a cable stayed bridge by analytical procedure is limited, field observations such as forced vibration test have been made. However, structural response developed by such forced vibration test is generally smaller in amplitude than that developed during a significant earthquake. Therefore it is often claimed that the damping ratio evaluated from the forced vibration test only gives the damping characteristics associated with small structural response. Evaluation of the damping characteristics which is actually developed during an earthquake is therefore of considerable interest.

* Member of JSCE, Dr. Eng. , Head of Earthquake Engineering Division, Earthquake Disaster Prevention Department, Public Works Research Institute, Ministry of Construction (Tsukuba Science City, Ibaraki-ken, Japan)

** Member of JSCE, Research Engineer, ditto.

*** Member of JSCE, Assistant Research Engineer, ditto. 
This study presents an analysis of the damping characteristics of a cable stayed bridge where strong motion records have been accumulated in the past three and a half years.

\section{SUIGO BRIDGE AND ITS DYNAMIC PROPERTIES}

Suigo Bridge is located at the border between Chiba-ken and Ibaraki-ken on National Road No. 51. Suigo Bridge consists of a two-span continuous cable stayed bridge as shown in Fig. 1 and steel plate girders which are placed on both sides of the cable stayed bridge. Total length of Suigo Bridge is $1040 \mathrm{~m}$. Because the cable stayed bridge is isolated from the adjacent steel plate girders, considered in this study is only the cable stayed bridge, and this is refered as the Suigo Bridge hereinafter.

The deck of the Suigo Bridge is of steel box girder with the length of $290.45 \mathrm{~m}^{33)}$. The deck is rigidly connected with a single steel tower with the height of $47.2 \mathrm{~m}$. The superstructure is supported by three substructures, i. e., two caisson foundations and a pile foundation. Fixed bearings are provided on the midsubstructure to connect and prevent the deck movement in both longitudinal and transverse directions. On the both end foundations, provided are movable bearings which prevent the deck movement in only transverse direction.

A series of forced vibration tests was conducted at Suigo Bridge soon after the completion to study the frequency and damping characteristics from the view point of aerodynamic stability analysis ${ }^{4}$. Two electric excitors, which produce sinusoidal force in vertical direction by rotating a set of unbalanced masses, were placed on the deck, and forced excitation for either vertical or torsional mode was made by synchronizing and anti-synchronizing the two excitors. Because the test was made to study aerodynamic stability, excitation in longitudinal and transverse directions, which are of significant importance for seismic design, was not made.

Natural modes and natural frequencies were accurately estimated for some of the lower significant modes from the steady-state oscillation of the superstructure. As an example of the test results, Fig. 2 shows resonant curves of response acceleration excited in vertical direction. They are normalized by the excitation force. Resonance corresponding to first through fourth vertical bending modes can be clearly observed. Mode shape was obtained by plotting the measured response acceleration at various locations along the deck. Fig. 3 shows the comparison between the observed and the computed mode shape for the first through fourth vertical bending modes. Predicted mode shape was computed with use of a discrete analytical model which will be described later. The measured mode shape of the deck is accurately predicted by the analytical model ${ }^{4)}$.

Damping ratio was estimated from logarithmic decay of the free oscillation from the steady-state vibration. Damping ratio of critical, which is estimated from the logarithmic damping ratio, is presented in

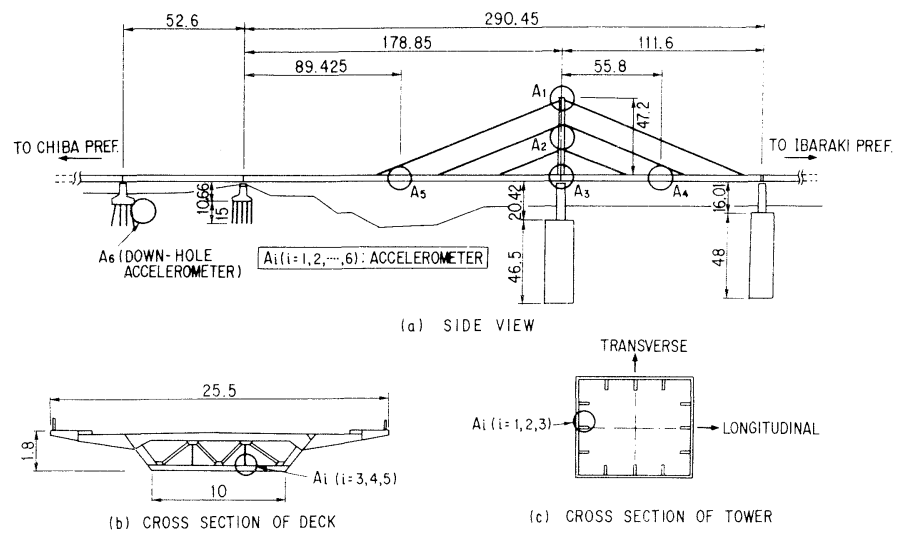

Fig. 1 Suigo Bridge. 


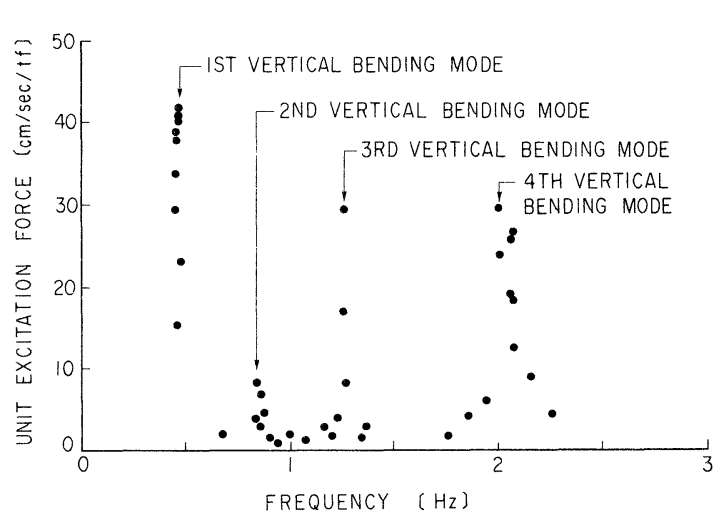

Fig. 2 Resonant Curve Obtained from Forced Excitation Test (4).

Table 1 Damping Ratio of Critical (\%) Estimated from Free Oscillation Test (4).

\begin{tabular}{|l|c|c|c|c|c|c|c|c|}
\hline \multicolumn{1}{|c|}{ MODE } & $1 \mathrm{ST}$ & $2 \mathrm{ND}$ & $3 \mathrm{RD}$ & $4 \mathrm{TH}$ & $5 \mathrm{TH}$ & $6 \mathrm{TH}$ & $7 \mathrm{TH}$ & AVERAGED \\
\hline $\begin{array}{l}\text { VERTICAL } \\
\text { BENDING MODE }\end{array}$ & 1.10 & 0.59 & 0.64 & 1.02 & 1.24 & 1.00 & 1.32 & 0.99 \\
\hline TORSIONAL MODE & 0.92 & 0.91 & 1.68 & 0.96 & - & - & - & 1.12 \\
\hline
\end{tabular}
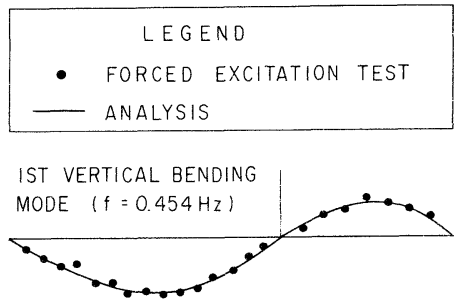

2ND VERTICAL BENDING MODE $(f=0.852 \mathrm{~Hz})$

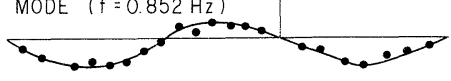

3RD VERTICAL BENDING $\operatorname{MODE}(f=1.26 \mathrm{~Hz})$

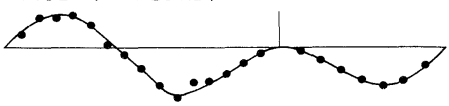

4TH VERTICAL BENDING $\operatorname{MODE} \quad(\mathrm{f}=2.03 \mathrm{~Hz})$

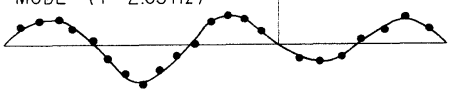

Fig. 3 Measured and Computed Mode Shapes (4)

Table 1. It varies depending on mode. The damping ratio averaged over the modes for which the damping ratio was estimated is $0.99 \%$ of critical for vertical bending mode and $1.1 \%$ for torsional mode.

\section{STRONG MOTION OBSERVATION AND STRONG MOTION RECORDS}

Strong motion observation has been made at the bridge since March 1986. Two horizontal-components force-balanced accelerometers are placed at six points as shown in Fig. 1, i. e., tower top (designated hereinafter as A 1 point), mid-height of the tower (A 2 point), bottom of the tower (A 3 point), center of the girder (A 4 and A 5 points), and $15 \mathrm{~m}$ below ground surface $50 \mathrm{~m}$ apart from the tower (A 6 point). A digital data acquisition system with a delay memory of 10 second is used so that acceleration records with equal time interval of $1 / 100$ second can be obtained.

Thirty five records have been so far obtained. Although most of them were developed by small earthquakes in magnitude, three records with sufficiently large accelerations were obtained by the earthquakes as shown in Table 2. Table 3 represents the peak acceleration thus obtained. The EQ-33 in Table 2 is the East Chiba-ken Earthquake which caused a large shaking with JMA Intensity of V at the Tokyo Metropolitan area on December 17, 1987.

As an example of the records, Fig. 4 shows the accelerations by the East Chiba-ken Earthquake (EQ-33). Of particular importance is the large response at the tower top (A 1 point) in transverse direction. Peak acceleration at A 1 point reached to 999.8 gal. Because the peak acceleration at the mid-height (A 2 point) and the bottom (A 3 point) of the tower is 471 gal and 173 gal, respectively, it is

Table 2 Magnitude and Location of Major Earthquakes.

\begin{tabular}{|c|c|c|c|c|c|c|c|}
\hline \multirow[b]{2}{*}{ EQ.NO. } & \multirow[b]{2}{*}{ DATE } & \multicolumn{3}{|c|}{ EPICENTER } & \multirow{2}{*}{$\begin{array}{l}\text { EPI CENTRAL } \\
\text { DISNTANCE }[\mathrm{Km}]\end{array}$} & \multirow[b]{2}{*}{ MAGNITUDE } & \multirow{2}{*}{$\begin{array}{l}\text { DEPTH } \\
{[\mathrm{Km}]}\end{array}$} \\
\hline & & LOCATION & LONGITUDE & LATITUDE & & & \\
\hline $\mathrm{EQ}-6$ & 1986.6 .24 & OFF CHIBA & $140^{\circ} 43^{\prime}$ & $34^{\circ} 49^{\prime}$ & 123 & 6.5 & 73 \\
\hline EQ-16 & 1987.2 .6 & OFF FUKUSHIMA & $141^{\circ} 54^{\prime}$ & $36^{\circ} 59^{\prime}$ & 173 & 6.7 & 31 \\
\hline EQ-33 & 1987.12 .17 & OFF CHIBAKEN & $140^{\circ} 29^{\prime}$ & $35^{\circ} 21^{\prime}$ & 62 & 6.7 & 58 \\
\hline
\end{tabular}


Table 3 Peak Accelerations at Suigo Bridge.

\begin{tabular}{|c|c|c|c|c|c|c|c|c|c|c|c|c|}
\hline \multirow{2}{*}{ EQ.NO. } & $\mathrm{A} 1$ & POINT & A2 & POINT & $\mathrm{A} 3$ & POINT & A4 & POINT & A5 & POINT & A6 & POINT \\
\hline & LG & TR & LG & $\mathrm{TR}$ & LG & TR & LG & TR & LG & TR & LG & TR \\
\hline $\mathrm{EQ}-6$ & 189 & 217 & 75 & 111 & 55 & 34 & 61 & - & 62 & 77 & 13 & 13 \\
\hline EQ-16 & 238 & 322 & 109 & 218 & 87 & 54 & 91 & - & 100 & 104 & 23 & 22 \\
\hline EQ-33 & 446 & 999.8 & 297 & 471 & 216 & 173 & 257 & - & 247 & 363 & 99 & 114 \\
\hline
\end{tabular}

1) LG and TR represent peak acceleration in longitudinal and transverse direction, respectively.

2) Records in transverse direction at A4 point were not obtained due to malfunction of the accelerometer.
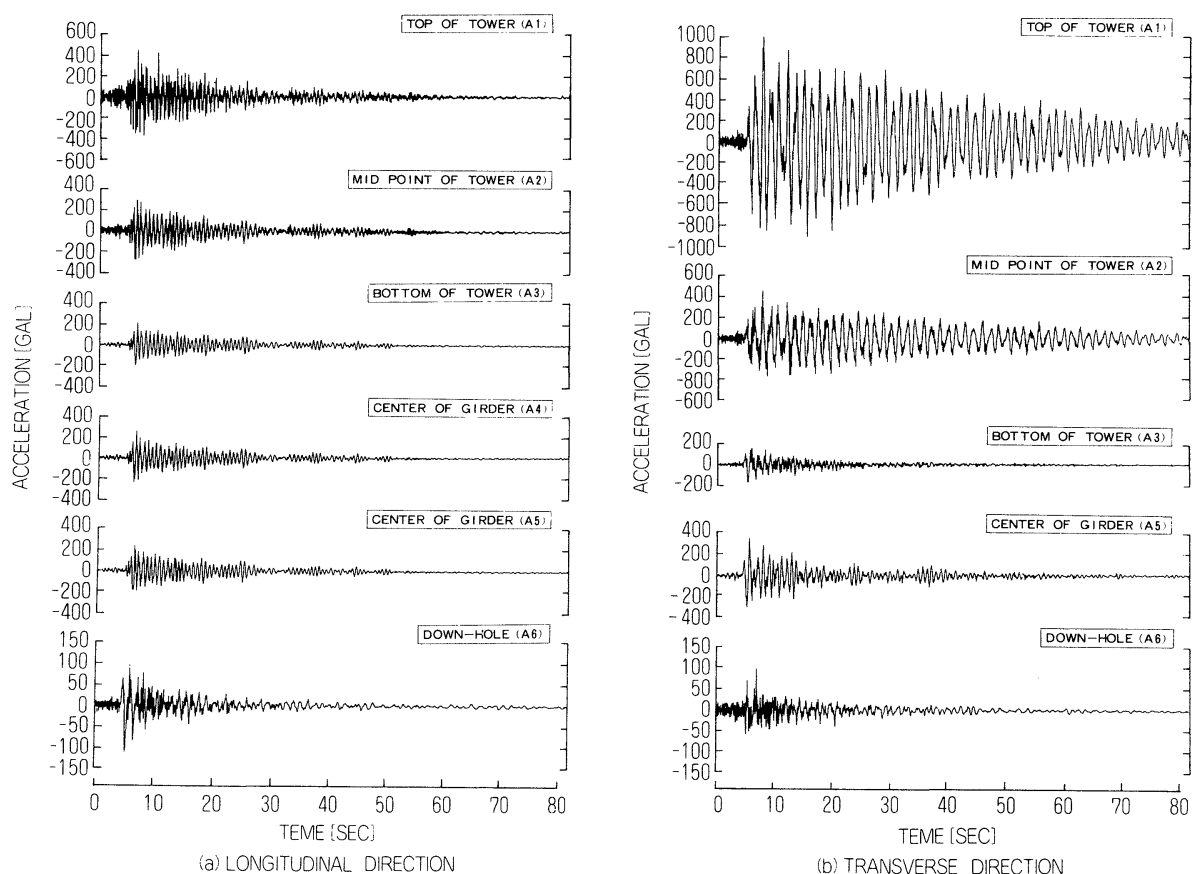

Fig. 4 Acceleration Records during East Chiba-ken Earthquake (EQ-33).

obvious that the tower vibrated in accordance with a cantilevered mode shape. In longitudinal direction, the peak acceleration is $446 \mathrm{gal}$ at tower top (A 1 point), $297 \mathrm{gal}$ at the mid-height (A 2 point) and 216 gal at the bottom of the tower (A 3 point), respectively. They are approximately 50\% smaller than those values in transverse direction.

\section{RESPONSE CHARACTERISTICS THROUGH ANALYSIS OF STRONG MOTION RECORDS}

Fig. 5 shows the Fourier spectra of the acceleration records presented in Fig. 4. Frequency of $1.51 \mathrm{~Hz}$ in longitudinal direction and $0.72 \mathrm{~Hz}, 0.87 \mathrm{~Hz}$ and $1.22 \mathrm{~Hz}$ in transverse direction is predominantly observed in the response of the deck and tower. Ground response recorded by the down-hole accelerometer has a predominant frequency of $0.87 \mathrm{~Hz}$ in both longitudinal and transverse directions. One can also note by carefully observing Fig. 5 that the frequency of $4.60 \mathrm{~Hz}$ in longitudinal direction and $5.26 \mathrm{~Hz}$ in transverse direction is also predominant in the response of the tower top (A 1 point).

To evaluate the vibration mode of the bridge, the acceleration records were processed with a band-pass filter, in which the center frequency was so adjusted that it matches with the predominant frequency observed in the Fourier spectra. Then, the acceleration amplitudes at the same instance after processed with the band-pass filter were plotted to obtain the vibration mode. Few variation of such vibration mode was observed even if the time instance for which the acceleration amplitudes are plotted is changed. Fig. 6 shows the vibration mode thus evaluated from the acceleration records. Translational mode with the 

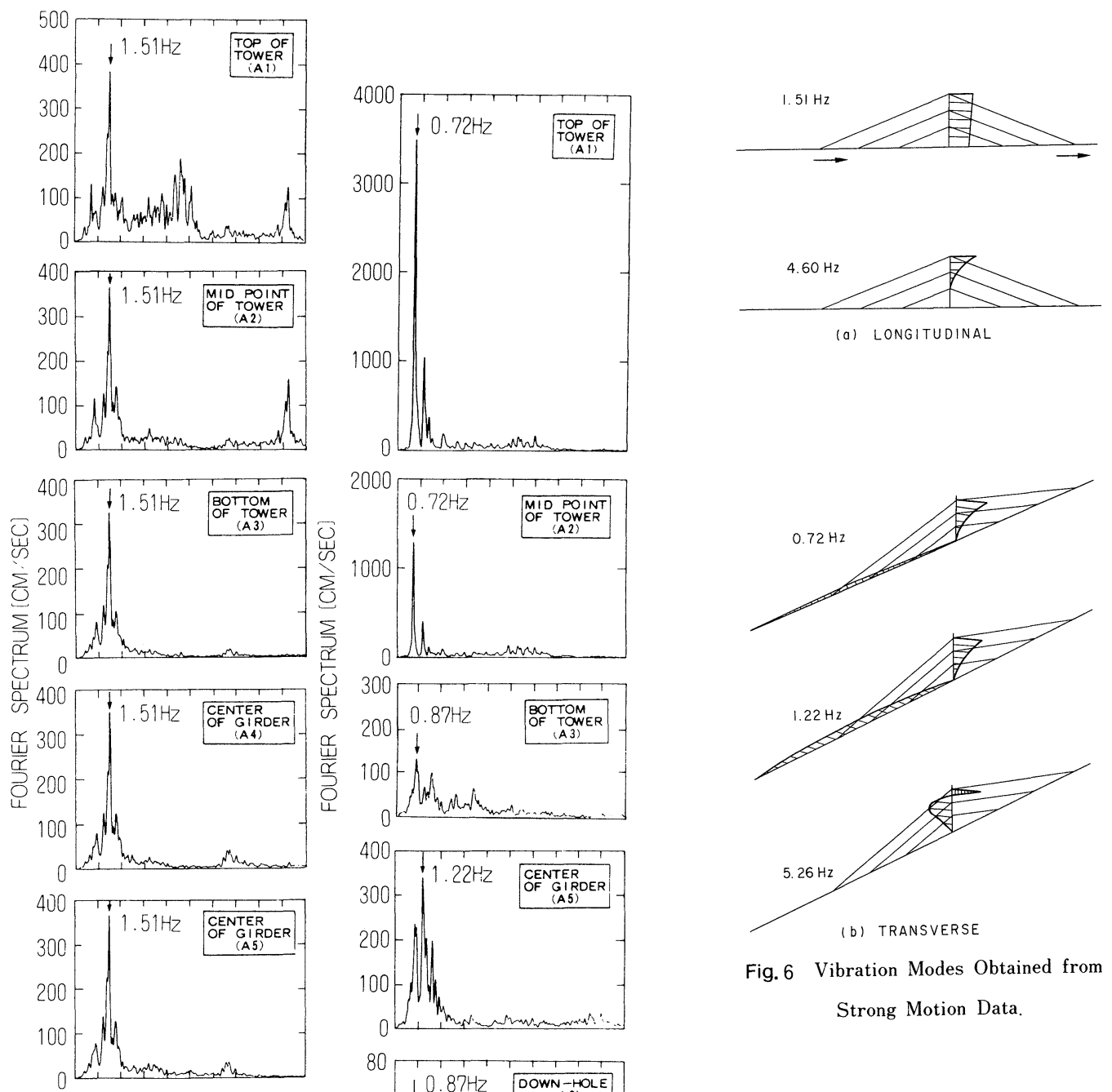

(a) LONGITUDINAL

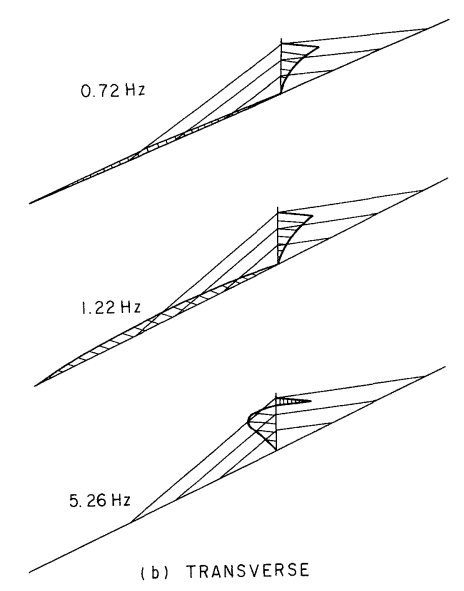

Fig. 6 Vibration Modes Obtained from Strong Motion Data.

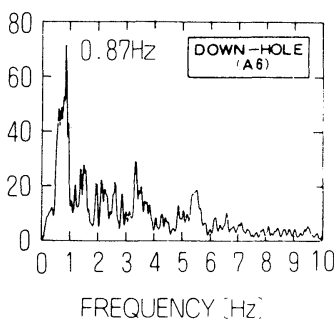

(b) TRANSVERSE DIRECTION

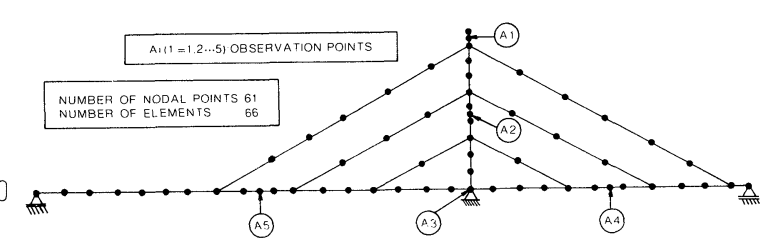

Fig. 7 Analytical Idealization.

(a) LONGITUDINAL DIRECTION

Fig. 5 Fourier Spectra of Strong Motion Record.

predominant frequency of $1.51 \mathrm{~Hz}$ and first flexural mode of the tower with the predominant frequency of $4.60 \mathrm{~Hz}$ are observed in the vibration mode in longitudinal direction. On the other hand, first and second flexural mode of the tower with the predominant frequency of $0.72 \mathrm{~Hz}, 1.22 \mathrm{~Hz}$ and $5.26 \mathrm{~Hz}$ are observed in the vibration mode in transverse direction.

To analyze the natural frequency and natural mode, Suigo Bridge was idealized by a linear discrete analytical model as shown in Fig. 7. The cross section and material properties were evaluated from the design calculation sheets. The cables are idealized as elastic beams with axial stiffness assuming zero stiffness for flexure. Because in the response in transverse direction the cable motion is decoupled with 


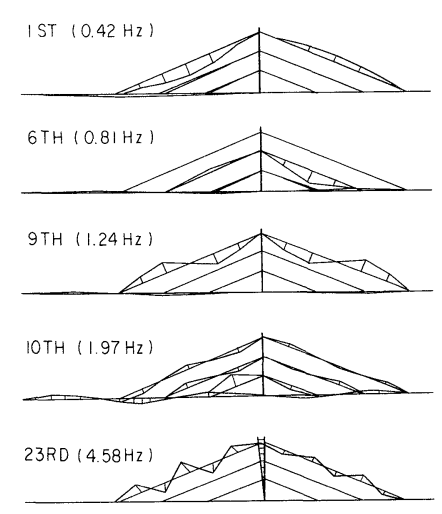

(a) LONGITUDINAL

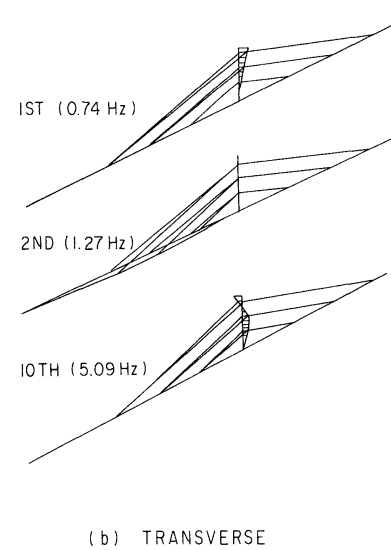

(b) TRANSVERSE

Fig. 8 Computed Mode Shapes.

the deck and tower motion, mass of the cable was disregarded, for simplicity, for analyzing the tower and deck response. Both ends of the deck, which are supported by the movable supports, are assumed free to move in longitudinal direction and fixed in transverse direction. Friction developed associated with relative movement of the deck at the movable supports was disregarded in the analytical idealization. Although the friction at the movable supports results in damping ${ }^{(i)}$, its effect for the computed natural mode and natural frequency is generally less significant for large bridges like Suigo Bridge.

Fig. 8 shows the mode shapes and natural frequencies computed for typical modes. It should be reminded here that the first through fourth vertical bending modes presented in Fig. 3, which were estimated from the forced vibration test, would correspond to 1st, 6th, 9th and 10th predicted mode, respectively. Computed natural frequencies and mode shapes for those vertical bending modes agree well with the measured values.

On the other hand, by comparing Fig. 8 with Fig. 6 , one can see how the computed modes agree with the measured vibration modes from the strong motion records. It is seen that the measured vibration mode in longitudinal direction with the predominant frequency of $4.60 \mathrm{~Hz}$ in Fig. 6 would correspond to the predicted 23 rd natural mode, because of the close agreement in both the frequency and mode shape. It is also seen that the measured vibration mode in transverse direction with the predominant frequency of $0.72 \mathrm{~Hz}, 1.22 \mathrm{~Hz}$ and $5.26 \mathrm{~Hz}$ in Fig. 6 would correspond to the predicted 1st, 2nd and 10th modes, respectively. However, it should be noted here that there is not a predicted mode which corresponds to the measured vibration mode in longitudinal derection with the predominant frequency of $1.51 \mathrm{~Hz}$. This is considered to be attributed to the assumption that the only superstructure of Suigo Bridge is idealized in the analytical prediction disregarding the substructure. Therefore, the mode shape was again computed by including the substructure into the analytical model, and a mode with a natural frequency of $1.52 \mathrm{~Hz}$, which has a mode with the translational motion of the tower, was obtained. Rocking motion of the foundation is predominantly developed in this mode. This results in the translation of the tower and the deck. Therefore, it is obviously understood that the vibration mode in longitudinal direction with the predominant frequency of $1.51 \mathrm{~Hz}$ is likely to correspond to the rocking motion of the substructure which supports the tower. It should be noted however that the inclusion of the substructure into the analytical idealization develops few differences in the predicted mode shape and natural frequency in the low frequency range, with the exception of the new inclusion of the predicted mode with the natural frequency of $1.52 \mathrm{~Hz}$. 


\section{DYNAMIC RESPONSE ANALYSIS OF SUIGO BRIDGE}

Damping characteristics of Suigo Bridge are analyzed through analytical simulations for the measured response by varying the damping ratio assumed in the analysis. The analysis is made by a standard modal analysis method assuming modal damping ratio $^{7}$. Because the response acceleration at the bottom of the tower (A 3 point) was recorded, it is prescribed to the A 3 point of the analytical model as an input motion, and the response of the superstructure is computed. Analytical idealization presented in Fig. 7 is used for the simulation.

The analysis is made separately for the response in longitudinal and transverse directions. In the response analysis in longitudinal direction, because the deck is supported by means of the movable supports at the both ends, the response acceleration measured at A 3 point is prescribed as an input motion only to this point, and the effect of friction at the movable bearings was disregarded. On the other hand, in the response analysis in transverse direction the analytical model is subjected to the same input acceleration measured at $\mathrm{A} 3$ point at the three supports, assuming that the deck response at both ends is identical with the response at $\mathrm{A} 3$ point.

It should be reminded here that the analytical model presented in Fig. 7 does not include the substructure. Inclusion of the substructure develops the mode with the natural frequency of $1.52 \mathrm{~Hz}$ which is predominantly observed in the measured acceleration. However as was described in the proceeding section because this mode is of rocking motion of the substructure, only rigid translation of the deck and tower occures. Because the measured response at the bottom of the tower (A 3 point) includes such movement as a result of the rocking motion of the substructure, disregard of this mode does not cause significant error to compute the response of the superstructure.

Damping ratio assumed in the analysis was varied as $0 \%, 1 \%, 2 \%$ and $5 \%$ of critical as a parameter to be studied. Although it is anticipated that the damping ratio varies depending on mode, it is assumed here the same for all modes because the dependence of the damping ratio on each mode is not known.

Analysis was made for the three records presented in Table 2. As an example, Fig. 9 shows comparative plots of acceleration time history between the measured and the predicted results at the tower top (A 1 point) and the center of the girder (A 5 point) for the East Chiba-ken Earthquake of December 1987 (EQ-33). It is obvious that the damping ratio of $0 \%$ gives larger response of the tower in longitudinal direction than the measured acceleration and that $5 \%$ damping ratio would be appropriate to develop a close correlation between the predicted and the measured accelerations. Overall predicted response accelerations assuming the $5 \%$ damping ratio agree well with the measured accelerations. However, for the response at the tower top (A 1 point) in transverse direction, the damping ratio of $5 \%$ is an overestimation, and $0 \%$ damping ratio would be appropriate. It is interesting to note such a clear difference in the damping ratio, which give the best correlation between the predicted and the measured responses at the tower, depending on the direction. On the other hand, for the deck response, 5\% damping ratio gives a nice agreement in both longitudinal and transverse directions. Although the comparative plots for other measuring points (A 2 and A 4) and for two other earthquakes are not presented here, agreement of the predicted response at those points with the measured acceleration is more or less the same with Fig. 9.

Fig. 10 shows the correlation of peak acceleration between the predicted and the measured. One can see how the predicted peak acceleration varies around the measured response in accordance with the changes of the damping ratio. Table 4 shows the damping ratio, which gives the best correlation for the peak acceleration, estimated from Fig. 10. Although it varies depending on the records, it is approximately $2 \%$ and $0-1 \%$ for the tower response in longitudinal and transverse directions, respectively, and is approximately $5 \%$ for deck response in both directions. It should be of course noted here that this damping ratio does not represent the one substantial to each structural components, but only gives the best 


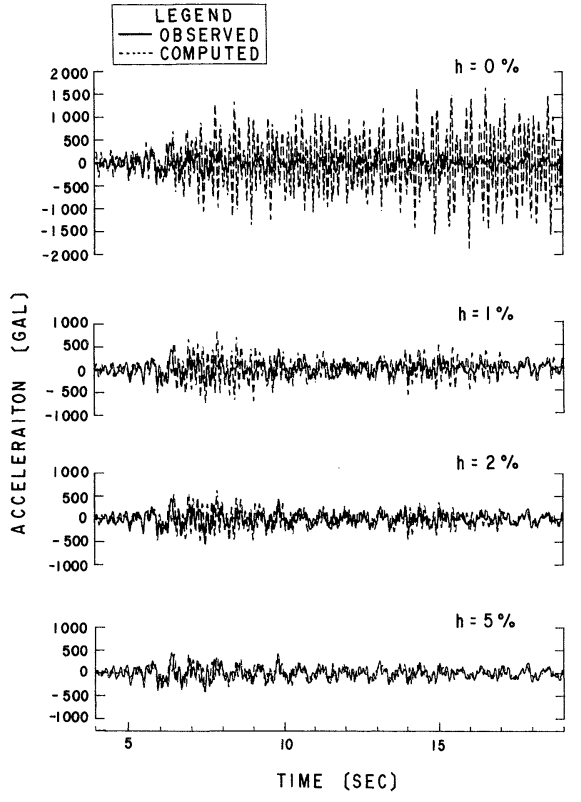

(a) LONGITUDINAL

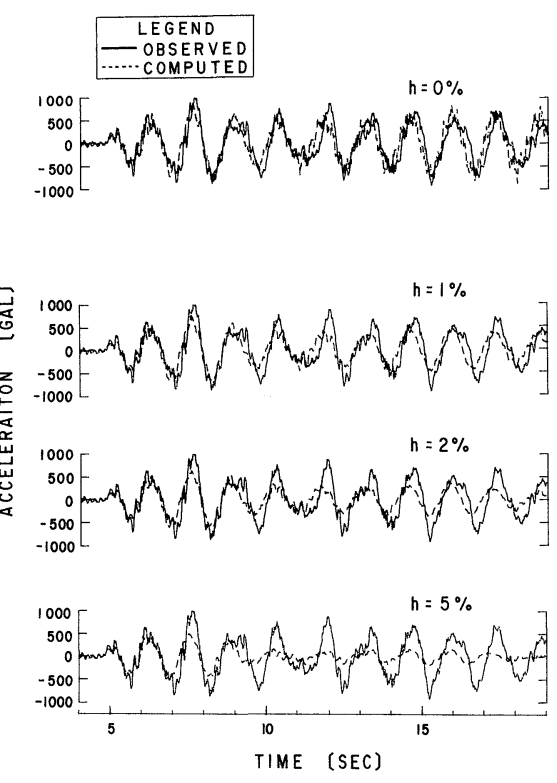

(b) TRANSVERSE

(1) Tower Top (A 1 Point)

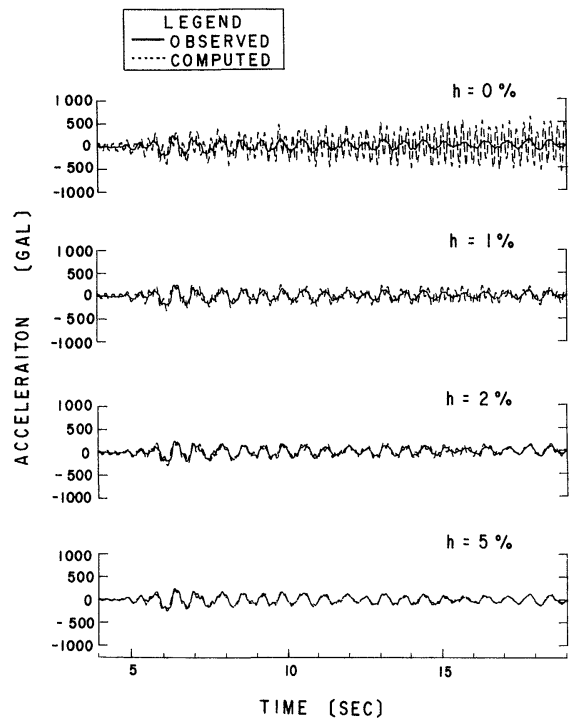

(a) LONGITUDINAL

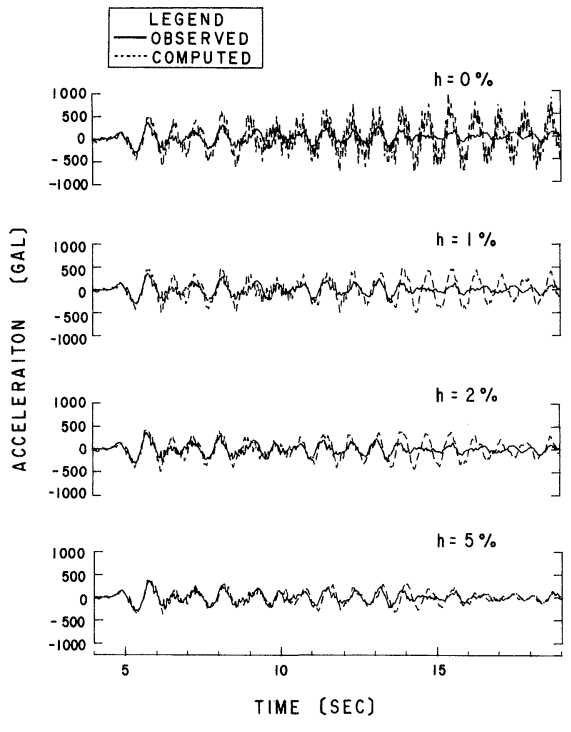

(b) TRANSVERSE

(2) Center of Deck (A 5 Point)

Fig. 9 Comparative Plot of Acceleration Response between Measured and Computed (East Chiba-ken Earthquake of December 17, 1987 (EQ-33)).

correlation at each recording point provided this value is assumed for all modes in the analysis. However, when the effect of mode coupling between the tower and the deck is less significant, the damping ratio presented in Table 4 may be approximately considered as the damping ratio associated with the tower and the deck.

It is interesting to compare the damping ratio presented in Table 4 with the one estimated from the forced vibration test. The forced vibration test gives the damping ratio of $0.99 \%$ and $1.1 \%$ of critical for 


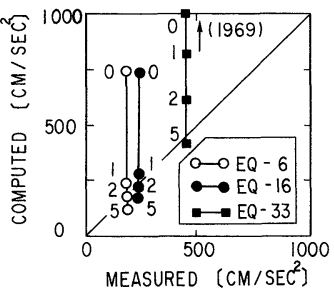

(a) LONGITUDINAL

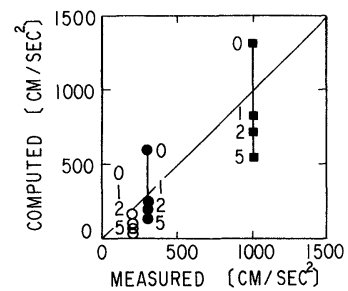

(b) TRANSVERSE

( AI POINT)

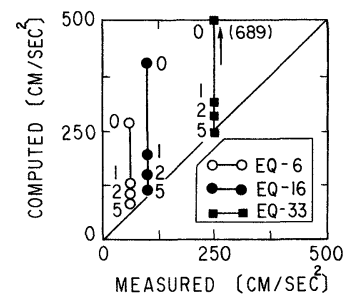

(a) LONGITUDINAL

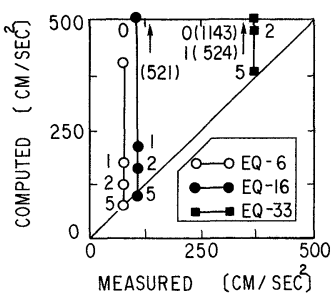

(b) TRANSVERSE

(2) CENTER OF GIRDER ( 55 POINT)

Fig. 10 Effect of Damping Ratio on Correlation of Peak Acceleration.

Table 4 Damping Ratio which gives the Best Correlation.

\begin{tabular}{|l|c|c|c|c|c|c|c|}
\hline \multirow{2}{*}{ EQ. NO. } & \multicolumn{4}{|c|}{ LONGITUDINAL } & \multicolumn{3}{|c|}{ TRANSVERSE } \\
\cline { 2 - 8 } & A1 & A2 & A4 & A5 & A1 & A2 & A5 \\
\hline EQ-6 & 2 & 5 & 5 & 5 & $0 \sim 1$ & 1 & 5 \\
\hline EQ-16 & 2 & 5 & 5 & 5 & $0 \sim 1$ & 1 & 5 \\
\hline EQ-33 & 5 & 5 & 5 & 5 & $0 \sim 1$ & 1 & 5 \\
\hline
\end{tabular}

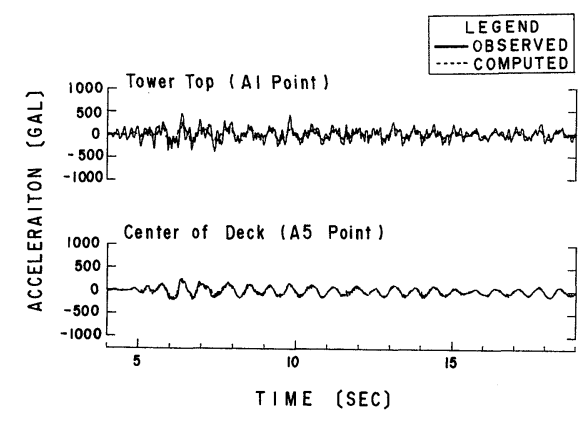

(a) LONGITUDINAL

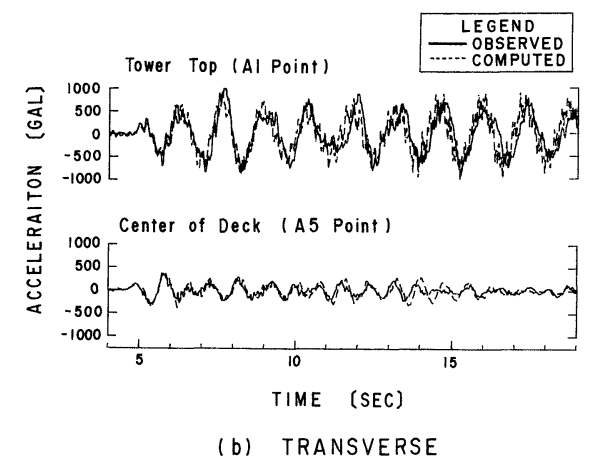

Fig. 11 Comparative Plot of Acceleration Response between Measured and Computed by Assuming Damping Ratio Estimated by Eq. (1).

the vertical bending and the torsional modes, respectively. These values are rather close with the ones presented in Table 4 for the tower, but are considerably smaller for the deck. The reason for such large discrepancy of the damping ratio may be attributed to the difference of mode shape and difference of amplitude of vibration, etc. Although this requires further analysis, it is of great importance to point out in this analysis that the damping ratio estimated for the response in longitudinal and transverse direction from the strong motion record is different from the one estimated for vertical and torsional modes from the forced vibration test.

It is also interesting to note the difference of the damping ratio of the tower depending on direction; the damping ratio of the tower in transverse direction is smaller than that in longitudinal direction. This may be due to the effect of cables. Because flexural rigidity of the cables is negligibly small, the tower is almost free to move from cables in transverse direction. Therefore the tower may be considered as a free standing column. Damping ratio of free standing column which is of steel box section is, generally, substantially small, and it seems reasonable to take a damping ratio of $0-1 \%$. On the other hand, in longitudinal direction, the tower is no more free standing column but is coupled with the deck by means of the cables. Therefore it is reasonable that the tower takes larger damping ratio in longitudinal direction than in transverse direction.

Finally, a response analysis was made assuming the damping ratio estimated as

$$
h_{i}=\frac{\sum_{j} h_{j} \phi_{i}{ }^{T} m_{j} \phi_{i}}{\sum_{j} \phi_{i}{ }^{T} m_{j} \phi_{i}}
$$


in which $h_{i}:$ damping ratio for $i$-th mode, $h_{j}:$ damping ratio assumed for $j$-th element, $\phi_{i}:$ mode vector for $i$-th mode, $m_{j}$ : mass matrix for $j$-th element. Damping ratio of the tower is assumed from Table 4 as $2 \%$ in longitudinal direction and $0 \%$ in transverse direction. Damping ratio of the deck is assumed as $5 \%$ in both directions.

Fig. 11 shows the comparison of acceleration response thus computed. Good agreement can be seen for both the tower and the deck.

\section{CONCLUSIONS}

For studying damping characteristics of Suigo Bridge, which is of two span continuous steel cable stayed bridge, an analysis was made for the strong motion records obtained at the bridge. Dynamic response analysis simulation was also made. From the results presented herein, the following conclusions may be deduced ;

(1) Damping ratio which gives best correlation in response analysis simulation for peak response acceleration is $2 \%$ and $0-1 \%$ of critical in longitudinal and transverse direction, respectively, for the tower, and $5 \%$ in both directions for the deck.

( 2 ) Damping ratio estimated from a forced excitation test is approximately $0.99 \%$ for vertical bending mode and $1.1 \%$ for torsional mode. The damping ratio estimated for the response in longitudinal and transverse direction from the strong motion records is substantially different from the one estimated for vertical bending and torsional modes from the forced excitation test.

(3) The fact that the mode shape for which the damping ratio is estimated is different seems the most favorable reason for such large discrepancy in the damping ratio described in (2).

\section{ACKNOWLEDGEMENT}

The authors express their sincere appreciation to Chiba Road Construction Office, Kanto Regional Construction Bureau of the Ministry of Construction, for their supports for strong motion observation at Suigo Bridge.

\section{REFERENCES}

1) Ito, M. : Damping Characteristics of Bridge Superstructure, KABSE, 1986 (in Japanese)

2) Kawashima, K., Unjoh, S. and Azuta, Y. : Seismic Design Procedure of Cable Stayed Bridge-Part 1 Dynamic Characteristics of Cable Stayed Bridge Based on Field Vibration Test Results-, Technical Note of the Public Works Research Institute, No. 2388, 1986 (in Japanese).

3) Shimizu, H., Ohta, Y. and Koyama, S. : Design and Construction of Suigo Bridge, Bridges and Foundations, Vol. 78, No.4, 1978 (in Japanese).

4) Narita, N. : Forced Vibration Test of Suigo Bridge, Technical Note of the Public Works Research Institute, No. 1349.1978 (in Japanese).

5) Kawashima, K., Unjoh. S. and Azuta, Y. : Seismic Design Procedure of Cable-Stayed Bridges-Part 6 Dynamic Characteristics of Suigoh Bridge Based on Strong Motion Records-. Technical Note of the Public Works Research Institute, No. 2673, 1988 (in Japanese).

6) Kawashima, K. and Unjoh, S. : Damping Characteristics of Cable Stayed Bridges associated with Energy Dissipation at Movable Supports, Structural Eng./Earthquake Eng., Vol. 6, No. 1, 1989.

7) Clough, R. W. and Penzien, J. : Dynamics of Structures, McGraw-Hill, 1975.

(Received September 1989) 